\title{
How to deal pituitary Adenomas: A Retro prospective Study
}

*Hosna Gomari, Mustafa Afifi, Wael El-Adl, Kreiter Serge, Henrik Suttmann, Rania Farouk el-Sayed,A M Attia

Department of Endocrinology.

*Corresponding Author : Hosna Gomari, Department of Endocrinology. E-mail: foroz@modares.ac.ir

Received date: July 18,2018 ;Accepted date : August 09,2018; Published date: September 16,2018.

Citation for this Article : Hosna Gomari, Mustafa Afifi, Wael El-Adl, Kreiter Serge, Henrik Suttmann, Rania Farouk el-Sayed,A M Attia. How to deal pituitary Adenomas: A Retro prospective Study. J. Endocrinology and Disorders. Doi: 10.31579/2640-1045/032

Copyright : (c) 2018 Hosna Gomari.This is an open-access article distributed under the terms of the Creative Commons Attribution License, which permits unrestricted use, distribution, and reproduction in any medium, provided the original author and source are credited.

\begin{abstract}
Pituitary adenoma (PA) is a benign primary tumor that arises from the pituitary gland and is associated with ophthalmological, neurological and endocrinological abnormalities. However, causes that increase tumor progressing recurrence and invasiveness are still undetermined.

Most adenomas are benign, approximately $35 \%$ are invasive and just $0.1 \%$ to $0.2 \%$ are carcinomas.Pituitary adenomas represent from $10 \%$ to $25 \%$ of all intracranial neoplasms and the estimated prevalence rate in the general population is approximately $17 \%$

Non-invasive and non-secreting pituitary adenomas are considered to be benign in the literal as well as the clinical sense; however a recent metaanalysis of available research has shown there are to date scant studies - of poor quality - to either support or refute this assumption.

\section{Etiology}

Adenomas which exceed 10 millimetres (0.39 in) in size are defined as macroadenomas, with those smaller than 10 mm referred to as microadenomas. Most pituitary adenomas are microadenomas, and have an estimated prevalence of $16.7 \%$ (14.4\% in autopsy studies and $22.5 \%$ in radiologic studies). A majority of pituitary microadenomas often remain undiagnosed and those that are diagnosed are often found as an incidental finding, and are referred to as incidentalomas.

Pituitary macroadenomas are the most common cause of hypopituitarism, and in the majority of cases they are non-secreting adenomas. While pituitary adenomas are common, affecting approximately one in 6 of the general population, clinically active pituitary adenomas that require surgical treatment are more rare, affecting approximately one in 1000 of the general population.
\end{abstract}

\section{Introduction}

All these adenomas, regardless of cell type, are invariably benign. Although often locally aggressive and invasive, they very rarely progress to true malignancy with documented extracranial metastases . Mechanisms underlying the constraints buffering pituitary adenomas against malignant transformation include development of DNA damage and premature proliferative arrest, i.e. cell senescence. Senescent pituitary cells are growth-constrained by CDK inhibitors including p21 for somatotroph tumors. P27 for corticotroph tumors and p15/p165 for non-functioning adenomas . These CDK inhibitors lead to cell cycle arrest, while maintaining differentiated hormone secretion and preventing the malignant transformation of respective adenoma cell types.

\section{Classification}

Unlike tumors of the posterior Pituitary, Pituitary adenomas are classified as endocrine tumors (not brain tumors). Pituitary adenomas are classified based upon anatomical, histological and functional criteria.

- Anatomically pituitary tumors are classified by their size based on radiological findings; either microadenomas (less than $<10 \mathrm{~mm}$ ) or macroadenomas (equal or greater than $\geq 10 \mathrm{~mm}$ ).

Classification based on radioanatomical findings places adenomas into 1 of 4 grades (I-IV):

Stage I: microadenomas $(<1 \mathrm{~cm})$ without sella expansion.

Stage II: macroadenomas $(\geq 1 \mathrm{~cm})$ and may extend above the sella.

Stage III: macroadenomas with enlargement and invasion of the floor or suprasellar extension.

Stage IV is destruction of the sella.
- Histological classification utilizes an immunohistological characterization of the tumors in terms of their hormone production.Historically they were classed as either basophilic, acidophilic, or chromophobic on the basis of whether or not they took up the tinctorial stains hematoxylin and eosin. This classification has fallen into disuse, in favor of a classification based on what type of hormone is secreted by the tumor. Approximately $20-25 \%$ of adenomas do not secrete any readily identifiable active hormones ('non-functioning tumors') yet they are still sometimes referred to as 'chromophobic'.

- Functional classification is based upon the tumors endocrine activity as determined by serum hormone levels and pituitary tissue cellular hormone secretion detected via immunohistochemical staining. The "Percentage of hormone production cases" values are the fractions of adenomas producing each related hormone of each tumor type as compared to all cases of pituitary tumors, and does not directly correlate to the percentages of each tumor type because of smaller or greater incidences of absence of secretion of the expected hormone. Thus, nonsecretive adenomas may be either null cell adenomas or a more specific adenoma that, however, remains nonsecretive.

\section{Methods}

\section{Description of subject}

One hundred forty one pituitary adenoma tissues and clinical patient data were collected at the Department of Neurosurgery of Hospital of Lithuanian University of Health Sciences between 2010 and 2016. Tumor tissues were frozen in liquid nitrogen immediately after their surgical resection. The age at the time of the operation, gender, relapse, size and diagnoses of Cushing syndrome, acromegaly or prolactinoma were collected for each patient. 
The endocrinological features were: 73 functioning and 68 nonfunctioning adenomas. According to the clinical findings functioning adenomas were: 7 growth hormone $(\mathrm{GH})$ - secreting adenomas, 2 insulin-like grow factor 1 (IGF-1) - secreting adenomas, 1 cortisol (COR) - secreting adenoma, 44 prolactin (PRL) - secreting adenomas, 1 adrenocorticotropic hormone (ACTH) - secreting adenoma and 18 adenomas secreting more than one hormone. According to tumor size all PAs were macroadenomas (greater than $10 \mathrm{~mm})$.

Invasion of pituitary adenomas were analyzed using MR imaging findings and classified according to Hardy classification, modified by Wilson. The Knosp classification system was used to quantify the invasion of the cavernous sinus. Invasiveness was established in 71 patients with pituitary adenoma. From them, 51 invasive and 20 noninvasive PAs were found.

\section{Nucleic acid extraction}

Tissue specimens were pulverized and stored at $-80{ }^{\circ} \mathrm{C}$ until DNA and RNA was obtained. Genomic DNA was extracted from 119 PA specimens by SDS/proteinase $\mathrm{K}$ treatment, followed by phenolchloroform extraction and ethanol precipitation. The remaining 22 samples were missing because of containing too small an amount of tumor tissue. All the samples were stored at $-20{ }^{\circ} \mathrm{C}$ until DNA was modified with sodium bisulfite.

Total RNA was extracted from 141 PAs using Trizol reagent, according to the manufacturer's protocol (Ambion, Life Technologies) and stored at $-80{ }^{\circ} \mathrm{C}$ until cDNA synthesis. However, 10 mRNA samples were lost because the concentrations for cDNA synthesis were too small. The genomic DNA and RNA concentrations and purity was determined using Nanodrop spectrophotometer (Eppendorf). For pure DNA, A260/280 is $\sim 1.8$ and for pure RNA A260/280 is $\sim 2$.

\section{Results}

\section{Targeting Cdk Signalling}

PTTG, pituitary tumor transforming gene, isolated from rat pituitary tumor cells is the index mammalian securin, and drives pituitary tumor formation in murine and zebrafish models. The gene is also induced by estrogen in experimental prolactinomas and is overexpressed in human pituitary tumor cells . In an attempt to recreate an ACTHsecreting pituitary adenoma, the zebrafish Pttg gene was linked to the POMC promoter to create a corticotroph targeted transgene. Transgenic zebrafish expressing pituitary corticotroph-directed zpttg develop phenotypic features which recapitulate human Cushing disease. These include corticotroph hyperplasia, hypercortisolism, hyperglycemia and fatty liver and cardiac effusions and hypertrophy . Furthermore, partial glucocorticoid resistance was also demonstrated.. Accordingly, R-Roscovitine, a selective CKD inhibitor, was shown to suppress tumorous pituitary POMC gene expression and ACTH secretion in both zebrafish and murine models of ACTH-secreting corticotroph cell adenomas. Suppressive effects of R-Roscovitine on ACTH secretion were also recapitulated in cell cultures derived from resected human pituitary tumor specimens. Based on these translational studies elucidating mechanisms for pituitary tumorigenesis, R-Roscovitine has now been approved to enter clinical trials to test for safety and efficacy in patients with ACTH-secreting pituitary adenomas and Cushing disease.

\section{Targeting Erb Signalling}

Mechanisms underlying prolactinoma pathogenesis are challenging to elucidate due to the unavailability of functional prolactin-secreting human pituitary tumor cell lines, as well as to the relative sparseness of available pituitary tumor tissue specimens. Both ErbB family receptors and ligands are expressed in normal anterior pituitary cells.Activation of this signaling pathway leads to induced PRL production by regulating PRL gene expression and lactotroph differentiation.
To further elucidate mechanisms underlying prolactinoma tumorigenesis, transgenic mice expressing EGFR or HER2 driven by the tissue-specific rPRL enhancer/promoter to achieve pituitary over-expression were generated lactotroph-targeted murine transgenic hEGFR/HER2 expression induced murine prolactinomas secreting high PRL levels a dual tyrosine kinase inhibitor (TKI) for both EGFR and HER2, hyperprolactinemia and tumor MAPK and Akt pathways were attenuated.

Furthermore, in both ACTH-secreting murine AtT20 cells, as well as in primary human cell cultures derived from resected ACTH-secreting tumors were suppressed by TKI treatment. In ATCH-secreting AtT20 cells, overexpression of EGFR led to activation of MAPK-Erk signaling, which was inhibited by gefitinib, an EGFR TKI.

\section{Conclusion}

Pituitary tumors are commonly encountered intracranial neoplasms which are invariably benign. Classic oncogene mutations are not encountered in these tumors, and disrupted cell cycle control and growth factor signaling likely contribute to pathogenesis and natural history. They exhibit unique clinical features which are determined by the secreted hormone gene product.

\section{References}

1. Chesnokova V, Zhou C, Ben-Shlomo A, Zonis S, Tani Y, Ren SG, Melmed S. Growth hormone is a cellular senescence target in pituitary and nonpituitary cells. Proc Natl Acad Sci U S A. 2013;110:E3331E3339.

2. Chesnokova V, Zonis S, Kovacs K, Ben-Shlomo A, Wawrowsky K, Bannykh S, Melmed S. p21(Cip1) restrains pituitary tumor growth. Proc Natl Acad Sci U S A. 2008;105:17498-17503.

3. Chesnokova V, Zonis S, Zhou C, Ben-Shlomo A, Wawrowsky K, Toledano Y, Tong Y, Kovacs K, Scheithauer B, Melmed S. Lineagespecific restraint of pituitary gonadotroph cell adenoma growth. PLoS One. 2011;6:e17924.

4. Cooper O, Mamelak A, Bannykh S, Carmichael J, Bonert V, Lim S, Cook-Wiens G, Ben-Shlomo A. Prolactinoma ErbB receptor expression and targeted therapy for aggressive tumors. Endocrine. 2014;46:318327.

5. Fukuoka H, Cooper O, Ben-Shlomo A, Mamelak A, Ren SG, Bruyette D, Melmed S. EGFR as a therapeutic target for human, canine, and mouse ACTH-secreting pituitary adenomas. $\mathbf{J}$ Clin Invest. 2011;121:4712-4721.

6. Heaney AP, Fernando M, Melmed S. Functional role of estrogen in pituitary tumor pathogenesis. J Clin Invest. 2002;109:277-283.

7. Herman V, Fagin J, Gonsky R, Kovacs K, Melmed S. Clonal origin of pituitary adenomas. J Clin Endocrinol Metab. 1990;71:1427-1433.

8. Jacks T. Tumor suppressor gene mutations in mice. Annu Rev Genet. 1996;30:603-636.

9. Liu NA, Jiang H, Ben-Shlomo A, Wawrowsky K, Fan XM, Lin S, Melmed S. Targeting zebrafish and murine pituitary corticotroph tumors with a cyclin-dependent kinase (CDK) inhibitor. Proc Natl Acad Sci U S A. 2011;108:8414-8419.

10. Liu X, Kano M, Araki T, Cooper O, Fukuoka H, Tone Y, Tone M, Melmed S. ErbB receptor-driven prolactinomas respond to targeted lapatinib treatment in female transgenic mice. Endocrinology in press 2014.

11. Melmed S. Acromegaly pathogenesis and treatment. J Clin Invest. 2009;119:3189-3202.

12. Melmed S. Mechanisms for pituitary tumorigenesis: the plastic pituitary. J Clin Invest. 2003;112:1603-1618.

13. Melmed S. Pathogenesis of pituitary tumors. Nat Rev Endocrinol. 2011;7:257-266.

14. Murdoch GH, Potter E, Nicolaisen AK, Evans RM, Rosenfeld MG. Epidermal growth factor rapidly stimulates prolactin gene transcription. Nature. 1982;300:192-194.

15. Pei L, Melmed S. Isolation and characterization of a pituitary tumortransforming gene (PTTG) . Mol Endocrinol. 1997;11:433-441.

16. Vlotides G, Eigler T, Melmed S. Pituitary tumor-transforming gene: physiology and implications for tumorigenesis. Endocr Rev. 2007;28:165-186. 